\title{
LA CONTAMINACIÓN DE GÉNEROS EN EL CINE \\ SOBRE EL MUNDO ANTIGUO
}

\section{ÓsCAR LAPEÑa MARCHENA \\ UNIVERSIDAD DE CÁDIZ}

\begin{abstract}
RESUMEN: En este trabajo queremos analizar la contaminación de géneros cinematográficos en el caso concreto del cine sobre el Mundo Antiguo. Una mezcla de influencias que se puede ver desde los inicios del cine y que incluye a prácticamente todos los géneros. Un apartado especial dentro de este trabajo lo dedicaremos a la contaminación con el género del terror, y en especial al filón de las momias egipcias.
\end{abstract}

PALABRAS ClAVE: Mundo Antiguo, Géneros Cinematográficos, Péplum, Momia egipcia.

\section{CONTAMINATION OF FILM GENRES IN THE CASE OF FILMS ABOUT THE ANCIENT WORLD}

\begin{abstract}
In this paper we analyze the contamination of film genres in the case of films about the Ancient World. A mixture of influences that can be seen from the beginning of the cinema and that includes virtually every genre. A special section of this paper will be devoted to pollution with the horror genre, and especially the reef of Egyptian mummies.
\end{abstract}

KEYWORDS: Ancient World, Film Genres, Peplum, Egyptian Mummie.

Recibido: 19-09-2015 / Aceptado: 04-01-2016 
Son variados y numerosos los criterios a los que se puede recurrir para realizar una catalogación de películas. Entre ellos podemos recordar el soporte en que están rodadas, el formato, el metraje, el tipo de producción, la calificación moral asignada o el género al que pertenecen. Los géneros cinematográficos fueron definidos por vez primera en una fecha tardía, allá por los años cuarenta del siglo $\mathrm{XX}^{1}$, cuando ya hacía tiempo que el cine había desarrollado un lenguaje indiscutiblemente propio; en ese momento se demarcaron los límites de los géneros que podemos denominar clásicos ${ }^{2}$-la tragedia, la epopeya, el drama, la comedia, el musical, el western, el cine bélico, el policiaco, el de terror, el histórico-, a los que posteriormente el paso del tiempo fue añadiendo otros de nuevo cuño, como el cine gore, el giallo, la road movie, el erótico, los mondo movie, el pornográfico, los buddy movie o el blockbuster.

Entre las diferentes definiciones existentes de género traemos a estas páginas aquella que sostiene que el género es una categoría que sirve para clasificar las películas dependiendo de las expectativas que éstas crean en el espectador ${ }^{3}$. La expectación viene propiciada por la publicidad que acompaña a los films, la cartelería con la que se intenta seducir a la posible audiencia, los tráiler que adelantan el contenido y la información básica al espectador, así como una propia película que puede, por si sola, crear un nuevo género.

En líneas generales los géneros pueden, a su vez, dividirse en canónicos -los enunciados en la década de los cuarenta del siglo pasado-, los híbridos -películas que participan de más de uno de los géneros canónicos-, y los llamados inter genéticos, es decir, aquellos títulos que trascienden esta división proponiendo una identidad propia y genuina ${ }^{4}$.

En principio, las películas ambientadas en el estricto marco cronológico del Mundo Antiguo pertenecerían al género clásico de cine histórico. Pero resulta que dentro de ese conjunto de films se pueden distinguir diferentes subgéneros que tienen unas características muy marcadas. Nos referimos al Kolossal italiano de los años del periodo mudo, que entre otros muchos ofreció títulos como La Caduta di Troia (G. Pastrone 1910), Quo Vadis? (E. Guazzoni 1912), o la fundamental Cabiria (G. Pastrone 1914). Al Epic estadounidense, que se desarrolló a lo largo de tres lustros que separaron el éxito de Samson and Delilah (C. B. DeMille, 1949), y el fracaso en taquilla de The Fall of the Roman Empire (A.

\footnotetext{
${ }^{1}$ SÁNCHEZ NORIEGA, J. L. Historia del cine. Teoría y géneros cinematográficos, fotografía y televisión, Madrid 2005, 96 ss.

2 CANO, P. L. "Géneros cinematográficos y mundo antiguo", en DUPLÁ, A. (Ed), El cine de romanos en el siglo XXI, Universidad del País Vasco, 2011, 59 - 77, 63 ss.

3 SÁNCHEZ NORIEGA, J. L. O. c. 98.

4 SÁNCHEZ NORIEGA, J. L. O. c. $99 \mathrm{~s}$.
} 
Mann, 1964). También se incluirían en esta categoría el cine histórico sobre la Antigüedad realizado en la Italia de los años cincuenta del siglo XX -Messalina (C. Gallone, 1951), Spartaco (R. Freda, 1953), Teodora imperatrice di Bisanzio (R. Freda, 1954) -; y especialmente el péplum, que entre los años 1958 (Le fatiche di Ercole, P. Francisci), y 1964 (Ercole, Sansone, Maciste, Ursus, gli invencibili, G. Capitani), reivindicó sin rubor la neo mitología a bajo coste.

Atendiendo a la clasificación anteriormente citada, el péplum y el epic serían géneros híbridos, ya que mezclan el cine histórico con el género de las aventuras ${ }^{5}$, en una estructura narrativa que se remonta a Cabiria.

Pero yendo un poco más allá y dejando al margen estos géneros o subgéneros dentro del cine histórico podemos hablar de otros pequeños filones más difíciles de encuadrar, como por ejemplos, el de los viajes en el tiempo de personajes de la Antigüedad (Cristo, Momias, Dioses Olímpicos...), o también el que se ocupa de la búsqueda en época contemporánea de objetos valiosos, especialmente reliquias o armas propiedad de destacados personajes del Mundo Antiguo. En estas películas la referencia a la Antigüedad es más bien tangencial, pero a pesar de eso deben tener su lugar en un estudio sobre el tratamiento cinematográfico del Mundo Antiguo.

Hablar de género y subgéneros nos lleva a mencionar la llamada contaminación de géneros, es decir, encontrar películas donde se dan cita algunas de las características definitorias de géneros muy diversos entre sí. En estas páginas queremos subrayar la abundancia de ejemplos de esa contaminación de géneros en películas ambientadas y relacionadas con el Mundo Antiguo.

Empezaremos ciñéndonos al subgénero del péplum. Recordemos que se trató de una producción fundamentalmente italiana, ya sea en solitario o en calidad de coproducciones con otros países europeos, que acabó con la crisis de la cinematografía transalpina de la segunda mitad de los años cincuenta del siglo XX -propiciada en buena medida por la llegada de la Televisión y el cambio de costumbres en el terreno del ocio que trajo consigo-, y que se convirtió en un filón extremadamente rentable hasta su agotamiento argumental a mediados de los años sesenta.

Entre los rasgos que mejor definen al péplum podemos recordar su carácter profundamente industrial -con reutilización de argumentos, repartos técnicos y artísticos, vestuarios, decorados e incluso escenas enteras-, el bajo coste de las producciones y su alta rentabilidad y, en el caso de Italia, su peculiar modelo de distribución centrado en la

${ }^{5}$ SÁNCHEZ NORIEGA, J. L. O. c. 100 y 177. 
periferia de los grandes centros urbanos, la poblaciones pequeñas y medianas y su proyección en el circuito de los oratorios religiosos ${ }^{6}$.

En cuanto a las películas que se engloban dentro del péplum ${ }^{7}$, estas se caracterizaban, básicamente, por un acusado maniqueísmo que en ocasiones derivaba hacia una presentación infantil de los acontecimientos; a ello hay que añadirle el desmedido afán por la espectacularidad y el colosalismo, característica esta que comparte con el epic estadounidense, aunque con bastante menos presupuesto ${ }^{8}$. El colosalismo pretendía llegar a todos los aspectos de la película: decorados, figurantes pero también a través de las emociones que se vivían en la pantalla y de los diálogos en los que se manifestaban. Pero no en la duración de las películas, que en el péplum rara vez pasaban de la hora y media de proyección. La búsqueda de espectacularidad terminaba afectando demasiado a la estructura de los films, ya que la acción se concentraba en unas pocas escenas, denominadas escenas núcleo, que eran las que más atraían la atención del público?.

En el péplum conviven la violencia -aunque con escasa presencia de la sangre-, y el erotismo que se manifiesta a través de determinados cauces como son las escenas de baile, de baños, de torturas o por las omnipresentes y semidesnudas esclavas. Aunque el elemento que sin duda mejor define e identifica al péplum es la presencia del héroe forzudo, ya que será alrededor de su cuerpo - que no de su personaje-, donde gire toda la trama de estas películas. El péplum es el género de los cuerpos hiperbólicos: el de los héroes y los de sus rivales, pero también los cuerpos femeninos que le rodean, bien sea para seducirlos o para confortarlos. Unos héroes, además, que entre sus características se encuentran la facilidad para viajar tanto en el tiempo como en el espacio.

Un último aspecto a reseñar del péplum es el argumento político de un amplio porcentaje de títulos, con narraciones que elaboran un discurso sobre la legitimidad y la restauración del poder político ${ }^{10}$. Que suele llegar, además, gracias a la intervención directa de los músculos del héroe y tras consumarse el habitual tiranicidio, otra de las constantes del género.

\footnotetext{
${ }^{6}$ DELLA CASA, S. “L'estetica povera del péplum”, en DE VINCETI, G. (Ed). Storia del Cinema Italiano. X. 1960 - 1964. Roma 2001, $306-318$.

${ }^{7}$ LAPEÑA, O. Guida al Cinema Péplum, Roma 2009, 15 ss.

${ }^{8}$ HUESO, A. L. Historia de los géneros cinematográficos, Valladolid 1976, 46 ss.

9 HUESO, A. L. "La Roma Imperial: Historia y espectáculo ante todo", en Historia y Vida, LVIII, 1990, 36 41,39 .

${ }^{10}$ LAPEÑA, O. “El discurso político del péplum”, en LAPEÑA O. \& PÉREZ MURILLO, M. D. (Eds), El poder a través de la representación fílmica, Université Paris Sud, 2015, 175 - 195.
} 
Sin abandonar los límites estrictos del péplum podemos hallar diversas muestras muy evidentes de contaminación de géneros. Podemos empezar con algunas mezclas con el cine de terror, género con el que el péplum comparte una característica fundamental como es el deseo de huir de la realidad ${ }^{11}$. El primer ejemplo que traemos a estas páginas es el film Ercole al centro della Terra, dirigido por Mario Bava en el año $1961^{12}$. En la película, el terror se canaliza a través de dos elementos básicos; por un lado está el episodio del descenso al Hades, representado con fuertes tonos rojos y azules que se van diluyendo en la niebla; una auténtica estética pop muy de la época y sobre todo muy trabajada por su director, que ha sido además uno de los grandes directores de fotografía del cine europeo ${ }^{13}$.

El otro elemento "terrorífico" de la película es el personaje de Licos; es el consejero habitual del péplum, cortesano de palacio que es, además, tío carnal de la princesa Deyanira, legitima gobernante del reino de Ecalia. Pero la originalidad que aporta el film es que Licos es un auténtico vampiro que, literalmente, se alimenta de la sangre y la energía a su sobrina; su carácter de verdadero vampiro viene subrayado por el hecho de que el actor que interpretó a Licos fue Chirstopher Lee; el espectador veía en pantalla al mismísimo conde Drácula trasladado al pasado mitológico combatiendo con Hércules.

En los carteles que publicitaban la película editados en los distintos países pueden apreciarse esas referencias al terror, en especial en el cartel estadounidense de la película, en donde junto a un cráneo puede verse a una mujer semidesnuda dentro de un ataúd, en una clara alusión a las vampiras que forman parte del ciclo cinematográfico del conde Drácula y que el espectador no encontrará en la película de Mario Bava ${ }^{14}$.

En ese mismo año -1961-, la figura del vampiro volvió a aparecer en el péplum, más concretamente en la película Maciste contro il vampiro (S. Corbucci \& G. Gentilomo). Aunque aquí abandona las referencias al personaje creado por Bram Stoker y se convierte en un personaje cercano al típico tirano del género que controla la ciudad de Salmanak utilizando para ello a un ejército de siervos encapuchados que extraen la sangre de los

\footnotetext{
11 RONDOLINO, G. \& LEVI, O. Catalogo Bolaffi del Cinema Italiano, Turín 1967, 185 s.

12 Otra clasificación ve la película como una mezcla de péplum, ciencia ficción y fantasía. CHIAVINI, R. \& PIZZO, G. F. \& TETRO, M. Il Grande Cinema Fantasy, Roma 2004, 30. Escenas del film de Bava, junto a otras de Ercole alle conquista di AtLANTide (V. Cottafavi, 1961), y de La vendetta di Ercole (V. Cottafavi, 1960), formaban buena parte del metraje del film La sfida dei Giganti (M. Lucidi, 1065), ilustrando la afirmación anterior de cómo en el péplum se reutilizaba todo, incluidas las propias películas. MENATINI, R. \& NOTO, P. "Dall'economia di scala all'intertestualitá di genere", en MANZOLI, G. \& PESCATORE, G. (Eds), L'Arte del risparmio: stile e tecnologia, Roma 2005, 19 - 30, 24.

${ }^{13}$ GIUSTI, M. Stracult. Dizionario dei film italiani, Milán 2004, 284. DELLA CASA, S. \& GIUSTI, M. Il grande libro di Ercole. Il cinema mitologico in Italia, Roma 2013, $130 \mathrm{s.}$

${ }^{14}$ CHAPMAN, D. Retro Stud. Muscle Movie Posters From Around the World, Portland 2002, 14.
} 
prisioneros para así alimentarlo ${ }^{15}$. Cobrak, el tirano de Salmanak, controla desde la sombra el poder político de la ciudad; comparte algunos aspectos con el Mad Doctor del cine de terror, entre ellas, su obsesión por capturar al héroe - Maciste-, al que quiere utilizar como modelo para su ejército de servidores vampirizados. Fuera de los límites del péplum pero siempre dentro del cine sobre la Antigüedad detectamos la presencia de vampiros en otras películas, como por ejemplo, en The Hunger (T. Scott, USA 1983), protagonizada por una antigua princesa egipcia que sobrevive hasta nuestros días gracias a la sangre de los amantes que debe procurarse.

Otro icono del cine de terror, el zombi, también encuentra su lugar en el péplum, concretamente en la película Roma contro Roma del director Giuseppe Vari en el año 1963. La acción transcurre en Asia Menor, a donde llega un centurión romano con la misión de investigar la misteriosa desaparición de soldados romanos. Las pesquisas le conducirán hasta el mago Aderbad quien, gracias a sus misteriosas y arcanas artes, resucita a los soldados muertos para reclutar un ejército con el que enfrentarse al Imperio ${ }^{16}$. De nuevo en la pantalla el espectador reconocía a un actor - John Drew Barrymore -, habitual del género del terror pero también del péplum, ya que en esos años había rodado algunos títulos en Italia. Su personaje de Aderbad, sacerdote y mago al mismo tiempo, se rodea, además, de toda una serie de ayudantes deformes que recuerdan a los mutantes fruto de los experimentos con hombres y animales de Island of lost souls (E. C. Kenton, USA 1932).

La película de Giuseppe Vari reutiliza imágenes de Costantino il Grande (L. De Felice), especialmente en las escenas que se desarrollan en el senado de Roma y en las de batallas, incluido el encuentro final con los soldados resucitados, en donde se juega con la música y el color para aumentar la sensación de terror. Los zombies de Roma contro Roma siguen el modelo haitiano que se canonizó en títulos como White Zombie (V. Halperin, USA 1932), y I walked with a rombie (J. Tourneur, USA 1943); los zombies (soldados en esta oportunidad), son únicamente unos esclavos sin voluntad alguna, muy alejados aún de la revolución en el género que se producirá apenas un lustro más tarde con Night of Living Dead, del director neoyorkino George A. Romero, en donde, para empezar, se deja sin responder a la cuestión de qué empuja a los muertos a volver a la vida y, sobre todo, asimila a los zombis a la figura del perfecto consumidor, que come/consume de todo y en todo momento y sin plantear nunca una sola queja ${ }^{17}$.

15 GIORDANO, M. Giganti Buoni. Da Ercole a Piedone (e oltre) il mito dell'nomo forte nel cinema italiano, Roma 1988, 171. BRUSCHINI, A. \& TENTORI, A. Mondi Incredibili. Il Cinema Fantastico-Avventuroso Italiano, Bologna 1994, 18 s. DELLA CASA, S. \& GIUSTI, M. O. c. 207 s.

${ }^{16}$ BRUSCHINI, A. \& TENTORI, A., O. c. 28. . DELLA CASA, S. \& GIUSTI, M. O. c. 261.

${ }^{17}$ LENZI, F. Zombi! Geroge A. Romero e il cinema dei morti viventi, Roma 2011, 13 ss. 
En Roma contro Roma hay, además, en la investigación que lleva a cabo el centurión romano una contaminación con el cine de detectives, algo que también podemos apreciar, por ejemplo, en Le legioni di Cleopatra (V. Cottafavi, 1959), o en Il figlio di Spartacus (S. Corbucci, 1962); en estos dos films hay una intriga política que a la postre los hace de difícil calificación.

No ha sido Roma contro Roma la única película en donde encontrar la acertada combinación entre Mundo Antiguo y género de zombis; nos referimos a la más reciente Morituris (R. Picchio, Italia 2008) ${ }^{18}$, en donde en el siglo XXI vuelven a la vida algunos de los gladiadores que acompañaron a Espartaco en el siglo I a. C., todo ello aderezado con evidentes influencias de elementos gore. En esta misma línea de producciones independientes, que se alejan conscientemente de los canales habituales de distribución y que apuestan por la utilización de todos los recursos comerciales y propagandísticos que ofrece internet, podemos citar dos ejemplos que tienen algunos aspectos comunes; el primero es que se trata de cortometrajes, y el segundo es que mezclan con total naturalidad y desparpajo la figura de Jesucristo con el cine de zombis en su versión más descarada y gamberra; nos referimos concretamente a The Passion of Zombie Jesus (I. Hunter, USA 2004), y Fist of Jesus (A. Cardona \& D. Múñoz, España 2012).

La contaminación de géneros dentro del péplum incluye también a aquellos que se encuentran muy alejados de las coordinadas cronológicas de la Antigüedad. Sería el caso de la ciencia ficción, en donde en su fusión con el péplum aporta una serie de ejemplos de lo más interesantes e innovadores. Las dos primeras referencias vuelven a ser producciones fechadas en el año 1961: Ercole alla conquista di Atlantide (V. Cottafavi), e Il gigante di Metropolis (U. Scarpelli).

La película dirigida por Vittorio Cottafavi señala un punto de inflexión en el péplum por la cantidad de lecturas diversas que sugiere, además de por ser -según algunas opiniones-, la obra más importante del género ${ }^{19}$. Ello se debe, especialmente, a la reescritura que hace del péplum y sobre todo por la deconstrucción que llega a realizar de la tradicional figura del héroe forzudo, que ya no actúa movido por una especie de bondad natural o por un alto sentido de la justicia, sino que lo hace cuando no tiene más remedio y prácticamente engañado por sus propios compañeros ${ }^{20}$.

${ }^{18}$ DUMONT, H. L'Antiquité au Cinema. Vérités, Légendes et Manipulations, Paris 2009, 301.

${ }^{19}$ BRUNO, E. "Spartacus. Ercole alla conquista di AtLANTide", en FilmCritica, no 114, 1961, 590 - 591, 591. SPINAZZOLA, V. "Le carnaval des demi deux", en Cinema 64, n 85, 1964, 42 - 85, 79. CASAS, Q. "La conquista de la Atlántide", en Dirigido por..., no 354, marzo 2006, 54 - 55.

20 SPINAZZOLA, V. Film 1963, Milano 1963, 107. 
Ercole alla conquista della Atlantide no solo es un ejemplo de contaminación del género del péplum con la ciencia ficción, sino que la película es, además, una fábula con citaciones a la mitología clásica, una sátira con ligeros toques de humor negro y una alegoría sobre el mundo actual con explícitas referencias a miedos contemporáneos; como la reciente experiencia del nazismo y la supuesta superioridad de la raza aria, las debilidades del sistema parlamentario, la bomba atómica o los primeros experimentos genéticos. Las alusiones al género de ciencia ficción más evidentes se manifiestan en la presentación del uranio como la base de la riqueza de la Atlántida, la energía atómica o el control de sus habitantes gracias al dominio científico que ejercen sus gobernantes, en particular la reina Antinea, una Circe reencarnada que ahora, en lugar de seducir a Ulises, intentará hacer lo propio con Hércules ${ }^{21}$. Algunas ideas y soluciones visuales de la película de Cottafavi han encontrado acomodo o bien han sido convenientemente reutilizadas en títulos posteriores, como, por ejemplo, en I Predatori di Atlantide (R. Deodato, Italia, 1983) ${ }^{22}$.

Una nueva muestra del control político de una comunidad mediante la manipulación científica y el monopolio de los avances técnicos se encuentra en la película $\mathrm{Il}$ Gigante di Metropolis (U. Scarpelli, 1961) ${ }^{23}$. A pesar del entorno agreste y lunar que la rodea, la ciudad de Metrópolis es una poderosa urbe cuya vida gira alrededor de los avances tecnológicos; la élite que gobierna la ciudad tiene a su disposición la capacidad de defenderse con rayos laser y radiaciones, el poder predecir los movimientos astrales y también la realización de trasplantes cerebrales y la posibilidad de acercarse al sueño de la vida eterna.

El último ejemplo de este tipo de contaminación lo tenemos en la más tardía Maciste e la Regina di Samar (G. Gentilomo, 1964) ${ }^{24}$; la soberana del reino de Samar cimenta su poder en unos monstruosos alienígenas -más exactamente selenitas ${ }^{25}$-, llegados a la tierra en un remoto pasado y a los que la reina debe ofrecer constantes y sangrientos sacrificios humanos. Además de alusiones a la ciencia ficción también se aprecian en el film

21 TOROK, J. P. "Le Maciste ne passera pas", en Midi Minuit Fantastique, no 6, 1983, 81 - 83, 81. WHITEHALL, R. "Days of strife and nights of orgy", en Films and Filming, no 10 / 3, 1963, 8 - 14, 14. SPINAZZOLA, V. "Significado e problema del film storico-mitologico", en Cinema Nuevo, no 176, 1965, 270 - 279, 279. RONDOLINO, G. \& LEVI, O. O. c. 186. SIARRI - PLAZANET, N. "Entretien. Vittorio Cottafavi. Des films contre le pouvo...", en Positif, no 456, 1999, 97 - 102, 99. MANZOLI, G. "La storia e la mitologia in sintesi. Vittorio Cottafavi alla conquista dei generi”, en Bianco e Nero, vol. N 559, 2007, 85 - 90, 87.

${ }^{22}$ DELLA CASA, S. "I Predatori di AtLANTide", en Film, no 6, 1984, 125.

${ }^{23}$ DAINELLI, P. P. "Peplum. Eroi musculari, fanciulle discinte e tanta cartapesta", en Amarcord, no 1, 1996, 32 - 47, 35. DELLA CASA, S. \& GIUSTI, M. O. c. 160 s.

${ }^{24}$ CHIAVINI, R. \& PIZZO, G. F. \& TETRO, M. O. c. 31 s. DELLA CASA, S. \& GIUSTI, M. O. c. 212.

${ }^{25} \mathrm{El}$ cartel estadounidense del film - allí se tituló Hercules against Moonmen, ya que el personaje de Maciste no tenía tirón en taquilla en Estados Unidos -, muestra junto a los alienígenas a un amenazador robot que no aparece en pantalla. CHAPMAN, D. O. c. 46. 
algunas pinceladas de terror, como el hecho de que el subterráneo reino de Samar evoque a la geografía infernal ${ }^{26}$.

Es habitual en el péplum que, cerca ya del final de la película, se produzca una catástrofe natural o un desastre provocado por los músculos del héroe que señala el postrero castigo a los malvados. Esos desastres puntuales y traumáticos acercan al péplum al género del cine de catástrofes. Además, hay otra serie de producciones que giran totalmente alrededor de uno de esos desastres; será el caso, por ejemplo, de títulos menos conocidos como Anno 79: la distruzione di Ercolano (G. Parolini, 1962), o L'incendio di Roma (G. Malatesta, 1965) ${ }^{27}$. Estos títulos están directamente vinculados con todas las versiones cinematográficas y televisivas realizadas de la novela The Last Days of Pompeii (1834); la obra de Bulwer Lytton no ha tenido mucho eco en el péplum, registrándose, eso sí, un único y original ejemplo -Gli Ultimi Giorni di Pompeii (1959)-, rodado por Sergio Leone pero firmada por el veterano director Mario Bonnard ${ }^{28}$. Si, en cambio, ha tenido mucha más repercusión dentro del kolossal italiano de principios del siglo XX así como en el epic estadounidense $^{29}$. De hecho, la última película filmada hasta el momento sobre el final catastrófico de la ciudad Pompeya -Pompeii (P. W. S. Anderson, USA / Alemania / Canadá, 2014), que no está basada en la novela de Lytton y que se abre con una cita de Plinio el Joven-, añade a la habitual y apocalíptica erupción del Vesubio nada menos que un maremoto. La razón es evidente: desde el tsunami del océano Índico del año 2004 y el de Japón de 2011 los maremotos se han convertido es una especie de tragedia recurrente en el mundo occidental; no en vano Internet está llena de imágenes de ambos cataclismos rodadas y fotografiadas por testigos de primera mano. A ello habría que añadirle el gran éxito de público cosechado en todo el mundo por la película Lo Imposible (J. A. Bayona, España / USA 2012), que recrea los sucesos del año 2004.

El péplum es un género que se caracteriza por tener un elevado porcentaje de escenas de acción, no solo batallas más o menos multitudinarias sino también abundantes combates y duelos. Si a ello se le suma la extraordinaria capacidad que tienen los héroes del péplum a la hora de viajar en el tiempo tendríamos como resultado la contaminación del género con otros como el de aventuras de capa y espada y -también muy próximo-, el del cine de piratas. Como ejemplos del primero traeríamos a estas páginas películas como Golia e il cavaliere mascherato (P. Pierotti, 1963) -que se desarrolla en la España del siglo XVI-, o

${ }^{26}$ FERNÁNDEZ VALENTI, T. "Imágenes cinematográficas del infierno: el Averno en la gran pantalla”, en NAVARrO, A. J. (Ed), El demonio en el cine. Máscara y espectáculo, Madrid 2007, 509 - 537, 516.

27 DELLA CASA, S. \& GIUSTI, M. O. c. 89 ss y $148 \mathrm{~s}$.

${ }^{28}$ FRAYLING, Ch. Sergio Leone. Algo que ver con la muerte, Madrid 2002, 102 ss.

${ }^{29}$ DUMONT, H. O. c. 517 ss. 
Maciste contro lo Sceicco (D. Paolella, 1962) -ambientada en el norte de África en la misma época que la anterior. Mientras que muestras de contaminación entre el péplum y el cine de piratas lo tenemos en Sansone contro i pirati (A. Anton, 1963), y Sansone contro il Corsaro Nero (L. Capuano, 1964), situándose en las Antillas en Edad Moderna la trama de ambos títulos.

Los continuos desplazamientos temporales de los protagonistas del péplum propician la contaminación entre géneros. De ese modo podemos encontrar a los diferentes héroes combatiendo con total naturalidad contra dinosaurios - compartiendo elementos con el cine "prehistórico" o cavernario -, como sucede en Maciste contro i mostri (G. Malatesta, 1962), o con Il Vendicatore dei Mayas (G. Malatesta, 1965), que recicla material de su película anterior ${ }^{30}$.

Los viajes en el tiempo pueden acabar produciendo mezclas de lo más curiosas, como aquella que une a personajes de la mitología griega con otros bíblicos; es lo que sucede en Ercole sfida Sansone (P. Francisci, 1963) ${ }^{31}$, en donde comparten vivencias y aventuras Hércules, Ulises, Dalila, Sansón y Penélope, todos ellos presentados como adolescentes más propios de una película de terror estadounidense que no de un péplum de los años sesenta. Como tantos otros pepla del momento, Ercole sfida Sansone fue en parte rodada en el cinematográfico barrio romano del $\mathrm{EUR}^{32}$.

También encontramos mestizajes del péplum con otro género que podemos definir como fundacional, como es el western, puesto que también narra el nacimiento mítico de una cultura. Y ese mestizaje se produce, bien porque personajes del péplum viajan hasta el Far West - transformándose en incuestionables cowboys, como sucede en Zorro contro Maciste (U. Lenzi, 1963), o en Sansone e il tesoro degli Incas (P. Pierotti, 1965) -, o bien porque la película adopta un planteamiento narrativo, una fotografía y una acción propia del western. Así, por ejemplo, en Romolo e Remo (S. Corbucci, 1961) ${ }^{33}$, el nacimiento mítico de Roma está narrada con la épica fundacional que caracteriza al género cinematográfico estadounidense por excelencia. Las similitudes con el western se inician ya con algunos de los carteles que publicitaban el film, así, en el cartel francés aparecen los dos hermanos frente a frente dispuestos a desenvainar sus espadas como si fueran pistolas. Romolo e Remo,

\footnotetext{
${ }^{30}$ DAINELLI, P. P. O. c. 30. Los diferentes carteles del film inciden mucho en mostrar la lucha de Maciste contra todo tipo de "monstruos prehistóricos". CHAPMAN, D. O. c. 98, 119, 123 y 126.

${ }^{31}$ LAPEÑA, O. "Pietro Francisci y el péplum", en SALVADOR VENTURA, F. (Ed), Cine y Autor, Santa Cruz de Tenerife 2011, 59- 75, 74 s.

32 DELLI COLLI, L. EUR é cinema, Roma 2008, 89.

${ }^{33}$ MOINE, R. I Generi del Cinema, Turín, 2005, 246.
} 
además, señaló el inicio de la decadencia en las pantallas de su protagonista, Steve Reeves, en el cine italiano, y por extensión en toda la industria cinematográfica ${ }^{34}$.

Las últimas referencias dentro del péplum nos conducen a consignar algunas muestras de la fusión del género con el de la comedia, llegándose al extremo de la auto parodia, ya sea esta pretendida o no. En ocasiones el humor viene de la mano de los ya referidos viajes en el tiempo de los personajes del péplum. En este apartado cabe citar películas como I baccanali di Tiberio (G. C. Simonetti, 1960), Maciste contro Ercole nella valle dei guai (M. Mattoli, 1961), o el film cuyo simple título ya ilustra la decadencia definitiva del filón que llega, especialmente, debido a la repetición y la sobreexplotación de los argumentos, nos referimos a Ercole, Sansone, Maciste e Ursus gli invencibili (G. Capitani, 1964) ${ }^{35}$.

Si abandonamos las estrechas fronteras del péplum y nos ocupamos de la producción cinematográfica ambientada o relacionada más tangencialmente con el mundo antiguo los ejemplos de cuanto hemos visto hasta ahora se multiplican de modo significativo.

Antes de que en Italia se desarrollara hasta el paroxismo el filón del péplum, la industria cinematográfica transalpina ya había realizado algunos interesantes ejemplos de cine histórico sobre el Mundo Antiguo. En algunos de estos títulos lo estrictamente histórico se contaminaba con el género del melodrama, como en Messalina (C. Gallone, 1951), o Spartaco (R. Freda, 1953). La película de Gallone, protagonizada por una actriz del carácter de la mejicana María Félix, presenta a la emperatriz romana como una mujer madura -nada que ver con la joven que aparecerá en pantalla en los años setenta y ochenta y más parecido a cómo se le muestra en The Robe (H. Koster, USA 1953), y Demetrius and the Gladiators (D. Daves, USA 1954)-, que se debate entre sus propios sentimientos y las exigencias del ejercicio del poder político. Por su parte, el Spartaco de Riccardo Freda continúa con la visión del personaje marcada en Italia por la novela homónima de Raffaello Giovagnoli (1874), alejándose, por lo tanto, de la tradición estadounidense de Espartaco que alcanza el máximo de popularidad e influencia con la película Spartacus, dirigida por Stanley Kubrick en 1961. La tradición italiana ve a Espartaco, ante todo, como un romano que combate la corrupción interna de Roma; nada por tanto de convertirlo en un abanderado de la lucha por la libertad en la concepción más moderna del término. En la película de Freda ese combate se mezcla con un trágico romance entre el gladiador y la hija de su feroz enemigo Craso. Todo ello convierte el film en una triste o agridulce reflexión

34 CHAPMAN, D. O. c. 64. DELLA CASA, S. "Sui generi: I pepla DELLA Titanus", en ZAGARRIO V. (Ed). Dietro lo schermo. Ragionamenti sui modi di produzione cinematografici in Italia, Venecia 1988, 59 - 62, 62.

35 DELLA CASA, S. \& GIUSTI, M. O. c. 142 s. 
acerca de los peajes que debe pagar cualquier intento de revolución o cambio para triunfar $^{36}$. En este sentido, la película de Freda estaría influenciada, conscientemente o no, por la novela The Gladiators (1939) del escritor húngaro Arthur Koestler, que traslada al siglo I a. C. diversas reflexiones políticas de su propia época.

Alejándonos del drama pasamos a un género opuesto como es el de la comedia; de nuevo abundan los ejemplos, aunque aquí queremos traer solo un par de títulos que nos parecen especialmente destacables. El primero sería Jupiter's Darling (G. Sidney, USA $1955)^{37}$; significativa película porque es de los pocos ejemplos que mezcla el cine histórico sobre la Antigüedad con la comedia musical y más en concreto con un auténtico subgénero dentro de ella como podríamos considerar los films protagonizados por la nadadora Esther Williams, en los que las coreografías subacuáticas eran la seña de identidad ${ }^{38}$. En Jupiter's Darling la trama se sitúa en el contexto de la II Guerra Púnica -como ya sucedía en Cabiria (G. Pastrone, Italia 1914)-, y aparecen en pantalla personajes históricos como Aníbal, Escipión o Fabio Máximo, salvo que en esta oportunidad están revisitados como si fueran las marionetas de una representación burlesca.

Otro ejemplo de comedia, con de nuevo un viaje en el tiempo incluido y al más puro estilo de A Connecticut Yankee in King Arthur's Court (1889), lo encontramos en la película Satiricosissimo (M. Laurenti, Italia 1970). Un film que aprovechaba por igual la campaña publicitaria puesta en marcha con ocasión de la adaptación de la obra de Petronio realizada tres añas atrás por Federico Fellini; así como del reclamo en la cartelera de la pareja de cómicos Franco y Ciccio y de una de las musa del giallo y de la comedia italiana, la actriz Edwige Fenech. La trama lleva a dos ineptos romanos del siglo XX a la corte del emperador Nerón.

La contaminación, o si se prefiere el intercambio de influencias narrativas y temáticas, con el género de intriga y detectives ofrece interesantes ejemplos, tanto ambientados en el pasado como en el presente. Entre los primeros destacan L'Inchiesta (D. Damiani, Italia 1986), y su remake dos décadas más tarde L Inchiesta (G. Base, Italia / España / Bulgaria / España / Francia, 2006) ${ }^{39}$. La historia que narran ambas películas es la investigación que lleva a cabo un tribuno romano en la Palestina del siglo I d. C. ante los

\footnotetext{
36 LAPEÑA, O. "The stolen seduction: the image of Spartacus in Riccardo Freda's Spartaco gladiatore DELLA Tracia”, en KNIPPSCHILD, S. \& GARCÍA MORCILLO, M. Seduction \& Power. Antiquity in the visual performing arts, Londres 2013, 171 - 182.

${ }^{37}$ SOLOMON, J. D. The ancient world in the cinema, Yale University 2001, $291 \mathrm{s.}$

38 Otros ejemplos de mezcla de cine musical con el mundo antiguo serían Jesus Christ Superstar (N. Jewison, USA 1973), o Joseph and the Amazing Technicolor Dreamcoat (D. Mallet, UK 1999), aunque con muy diferentes pretensiones en cada uno de estos títulos.

${ }^{39}$ DUMONT, H. O. c. 433 s y 448 s.
} 
rumores de que Cristo no ha muerto realmente; la búsqueda de su cuerpo sería la prueba de que realmente la condena de Poncio Pilatos se llevó a cabo. El cuerpo de Cristo es de nuevo protagonista en The Body (J. McCord, USA / Israel / Alemania, 2001): en esta ocasión la trama se traslada a la conflictiva Jerusalén de finales del siglo XX, en donde el hallazgo en una excavación arqueológica del cadáver de un crucificado datado en el siglo I d. n. e. desata una violenta tormenta política que afecta a los Estados Unidos, el estado de Israel y también al Vaticano.

En otras oportunidades no son los vestigios de Cristo los protagonistas de las películas, sino lo que podemos denominar, las reliquias de la pasión, tal y como sucede en el film Revelation (S. Urban, UK, 2001), en donde la trama gira en torno a la búsqueda de una misteriosa caja realizada con las maderas y los clavos de la cruz de Cristo. En este tan particular mini subgénero también podríamos incluir la producción para televisión alemana Das Jesus Video (S. Nieman, 2002), que como su propio título ya indica narra las vicisitudes de una cámara de video que contiene la grabación de los hechos de la pasión y resurrección de Jesucristo.

Seguramente el género con el que más influencias y contaminación se pueden detectar es el del terror, y ello se debe en buena medida a que aquí habría que incluir el amplio repertorio de películas protagonizadas por momias egipcias, seguramente el personaje colectivo de la Antigüedad que más ha aparecido en las pantallas de cine. Dentro de este particular subgénero podemos subrayar la existencia de una serie de hitos que marcaron un antes y un después. Qué duda cabe que el primero de ellos fue el éxito de la Universal The Mummy (K. Freund, USA 1932) ${ }^{40}$, una acertada combinación de terror, intriga y romance que se le ofrecía a un público que aún tenía reciente en la memoria el impactante hallazgo -muy seguido por los medios de comunicación-, del tesoro de Tutankamón y las supuestas y ancestrales maldiciones puestas en marcha con la apertura de la tumba.

Pero antes del gran éxito de la película de Freund y de Boris Karloff el antiguo Egipto había estado presente en el cine desde sus mismos orígenes. Dejando a un lado las películas que se ocupan de Cleopatra, el Egipto romano y las adaptaciones de la Aída de Verdi, la civilización de los faraones ha estado presente en las pantallas mediante unos cauces muy definidos. En primer lugar como simple excusa para mostrar los nuevos efectos visuales que ofrecía la novedad del cinematógrafo. Se trata de breves bobinas en donde Egipto se ve reducido a un esqueleto, o un cadáver que de improviso cobra vida;

${ }^{40} \mathrm{El}$ año anterior la Universal ya había rodado sus versiones de Dracula (T. Browning), y de Frankenstein (J. Whale). SENN, B. Golden Horrors, Jefferson 1996, 204. CASAS, Q. "La Momia. Karl Freund", en Dirigido por..., n 290, mayo 2000, 36 - 37. GÓMEZ RIVERO, A. "La momia clásica: el monstruo, el mito", en NASCHY, P. et altri, La marca de la momia, Madrid 2008, 46 - 132, 57 ss. 
hablamos de títulos como The Haunted Curiosity Shop (W. R. Booth, UK 1901) ${ }^{41}$, Le monstre (G. Melies, Francia 1903), o The Mummy (Prod. Tanhauser, USA 1911), en donde una chica es momificada en un experimento con la ayuda de la electricidad ${ }^{42}$.

Otro de los cauces a través de los cuales el antiguo Egipto era mostrado en pantalla era a través de objetos - habitualmente joyas y elementos funerarios -, que portan consigo la venganza y la tragedia hasta el presente; estos elementos los podemos encontrar en películas como The Egyptian Mystery (J. Searle Dawley, USA 1909) ${ }^{43}$, la cinta danesa Mumiens Halsband (R. Dinesen 1915) ${ }^{44}$, The silent mystery (F. Ford, USA 1918), La perla di Cleopatra (G. Brignone, Italia 1922), también conocida con el título de I Figli del Nilo y que mezcla el Egipto esotérico con el, en aquel momento muy de moda, cine de héroes acrobáticos $^{45}$, o The fortieth door (G. B. Seitz, USA 1924).

En otras oportunidades Egipto vuelve al presente de manera amenazadora mediante el recurso a ceremonias ocultistas o directamente a través de reencarnaciones que llevan hasta época contemporánea a personajes del pasado. En este apartado tienen cabida películas como The Princess in the vase (W. McCutcheon, USA 1908) ${ }^{46}$, When soul meets soul (J. Farrel McDonald, USA 1912), Lord John in New York (E. LeSaint, USA 1915), o His Egyptian Affinitiy (A. Christie, USA 1915) ${ }^{47}$.

Puede resultar paradójico que hasta el éxito de la película de Freund -aunque de hecho esta tendencia seguirá mucho después, sobre todo con las producciones de animación destinadas a un público infantil-, el personaje de la momia ha tenido cabida en infinidad de comedias. Centrándonos en los primeros años del cine se pueden encontrar diferentes títulos en donde los personajes se disfrazan más o menos burdamente de momias, o bien éstas cobran repentinamente vida, propiciando situaciones cómicas o solucionando felizmente complejas intrigas amorosas. Ejemplos de ellos son títulos como Wanted, a Mummy (A. E. Coleby, UK 1910) ${ }^{48}$, La Momie (A. Capellani \& H. Desfontaines,

\footnotetext{
${ }^{41}$ LANT, A. "Spazio per la razza in Cabiria", en BERTETTO, P. \& RONDOLINO, G. (Eds), Cabiria e il suo tempo, Turín 1998, 212 - 222, 220. LANT, A. "La maledizione del faraone: come il cinema contrasse l'egittomania" en BAZZOLI, M. S. \& GARIAZZO, G. Onde dell desiderio. Il cinema egiziano delle origini agli anni settanta, Turín 2001, 15 - 29, 23. GÓMEZ RIVERO, A. O. c. 52.

${ }^{42}$ KINNARD, R. Horror in silent films. A filmograpby 1896-1929, North Carolina 1995, 44. POLLÉS, R. La Momie de Khéops à Hollywood, París 2001, 313.

${ }^{43}$ KINNARD, R. O. c. 29. POLLÉS, R. O. c. 312.

44 POLLÉS, R. O. c. 313.

45 Protagonizada en esta ocasión por el personaje de Ajax. CHITI, R. Dizionario dei registi del cinema muto italiano, Roma 1997, 41. MARTINELLI, V. Il Cinema Muto Italiano. 1921 - 1922, Roma 1981, 469 s.

${ }^{46}$ KINNARD, R. O. c. 26. POLLÉS, R. O. c. 312.

${ }^{47}$ KINNARD, R. O. c. 73. POLLÉS, R. O. c. 313.

${ }^{48}$ KINNARD, R. O. O. c. 40.
} 
Francia 1911), Didled! (C. Calvert, UK 1912) ${ }^{49}$, The Egyptian Mummy (L. Beggs, USA 1914) ${ }^{50}$, o la producción italiana Una donna, una mummia, un dilplomatico (C. De Riso, 1920) ${ }^{51}$.

Además del éxito que supuso la versión de Boris Karloff podemos destacar otros hitos dentro de tan particular género. Así, en la década de los años 40 hay que subrayar la tetralogía protagonizada por la momia Kharis, que traslada la acción ya a los Estados Unidos, y que de nuevo fue producida por la Universal; estaba compuesta por las películas The mummy's hand (C. Cabanne, USA 1940), The mummy's tomb (H. Young, USA 1942), The mummy's curse (L. Goodwins, USA 1944), y que finalizó con The mummy's ghost (Ch. Le Borg, USA 1944$)^{52}$. La saga, que salvo el primer título, estuvo inteprepatada por el actor Lon Chaney Jr. aportaba la novedad -además del comentado traslado de la amenaza a suelo estadounidense-, de que la momia Kharis es un auténtico no muerto que recobra ocasionalmente la vida gracias a las pócimas y a la atención y el cuidado de unos seguidores fieles y fanáticos que instrumentalizan el peligro que supone la presencia de la momia.

El siguiente hito que podemos consignar tiene lugar en el año 1959 con el estreno de The Mummy (T. Fisher, UK) ${ }^{53}$, la revisión en clave neogótica y a todo color que de los éxitos del terror de la Universal realizó la productora británica Hammer. A la película de Terence Fisher -y que contó como pareja protagonista a Christopher Lee y Peter Cushingsiguieron otros títulos como The curse of Mummy's Tomb (M. Carreras, 1964), The Mummy's Shroud (J. Gilling, 1967), y Blood from the Mummy's Tomb (S. Holt, 1971) ${ }^{54}$. Como ya sucedió con las revisiones de los mitos cinematográficos de Drácula y de Franskenstein, en el caso de la Momia, la Hammer aumento las dosis de erotismo y de violencia para adaptarla a los nuevos tiempos y al nuevo tipo de público que consumía este cine; pero al mismo tiempo la película de Terence Fisher - en donde la momia vuelve a llamarse Kharis-, devolvía al monstruo la capacidad de decisión y actuación, ya no era un simple trozo de carne muerta como sucedía en las cintas de los años cuarenta.

Hasta el momento el último gran fenómeno a nivel de público y mediático del cine sobre momias llegó en el cambio de milenio con las películas The Mummy (S. Sommers, USA 1999), y The Mummy's returns (S. Sommers, USA 2001). En ambas la figura de la momia aparece en segundo plano, eclipsada tanto por los abundantes efectos visuales como

49 HERNÁNDEZ DESCALZO, P. J. "Luces, cámara, jacción!: Arqueología, Toma 1", en Complutum, 8, 1997, $311-334,321$.

${ }^{50}$ KINNARD, R. O. c. 62. POLLÉS, R. O. c. 313.

${ }^{51}$ MARTINELLI V. Il Cinema muto Italiano. 1920, Roma 1980, 108.

${ }^{52}$ LEUTRAT, J. L. "El reloj y la momia. Variaciones sobre Egipto y el cine", en Arcbivos de la Filmoteca, $\mathrm{n}^{\circ} 25$ - 26, 1997, 196 - 223, 212. EUGENI, R. La relazione d'incanto. Studi su cinema e ipnosi, Milán 2002, 204. GÓMEZ RIVERO, A. O. c. 71 ss.

${ }^{53}$ NAVARRO, A. J. "La Momia. Terence Fisher", en Dirigido por..., n n 290, mayo 2000, 48 - 49.

${ }^{54}$ COZZI, L. Hammer. La fabbrica dei mostri, Roma 1999, 92 y 149. GÓMEZ RIVERO, A. O. c. 99 s. 
por la figura del héroe, moldeado según el arquetipo del arqueólogo explorador y aventurero que se consolida y alcanza su máxima expresión en la figura de Indiana Jones. Aunque la existencia de todos estos hitos no deben hacer olvidar que la momia ha sido un personaje omnipresente desde los orígenes del cine hasta hoya día, y que no ha cesado de aparecer en las pantallas, las de cine y las de televisión, ya sea en cintas de terror, comedias, películas de animación destinadas a una audiencia infantil o cine para adultos.

Alrededor de la momia cinematográfica se ha ido elaborando un discurso al tiempo anticolonialista y de amenaza a algunos de los fundamentos de la sociedad occidental. En él, la momia asume el elemento irracional e hiperbólico con el que a simple vista se suele identificar con todo lo oriental. La momia, en especial en las versiones de 1932 y 1959, tiene un marcado carácter hipnótico y seductor que culmina con el rapto de la esposa, prometida o pareja del arqueólogo que -consciente o inconscientemente-, la devolvió a la vida. La seducción y fuga de la pareja de enamorados/cautivados atenta directamente contra la base de la familia occidental; el tedio y el ensimismamiento laboral con que se presentan a los arqueólogos contrasta con el poderío físico que denota un deseo que supera los límites temporales y que acaba por seducir a la mujer. Una seducción que al final viene justificada por utilizar recursos mágicos o hipnóticos, pero que no deja de ser la victoria de los sentidos, del elemento sensual frente a la razón sobre la que se levanta el mundo científico de los hombres. De los hombres blancos y occidentales, claro está. En este planteamiento, además, se lanza la idea de que el punto débil de occidente no es otro que la mujer, la fisura por donde la amenaza oriental puede entrar.

Las películas de momias, además, plantean el debate del saqueo cultural y patrimonial llevado a cabo por países europeos en territorios conquistados política o económicamente; tan interesante como las momias, en estas películas, es el papel que se les atribuye a los arqueólogos, sus oponentes. Al margen de que en pantalla se consolida una idea de que la arqueología es una aventura y no una labor y un aprendizaje, en donde el azar juega un papel fundamental y en donde el fin último es el hallazgo del objeto -tesoro, tumba o momia, da igual-, y no las cuestiones sociales, políticas, económicas o culturales a las que se puede responder con el mencionado hallazgo. El arqueólogo cinematográfico es un cazador de piezas del pasado, que viste como los cazadores blancos que irrumpen y amenazan el orden natural y benévolo del mundo de Tarzán. Su ambición viene justificada por el poderío político y militar de la nación a la que pertenece, su superioridad en esos campos en el presente les facilita la tarea de esquilmar el pasado de los sometidos. 
Frente a ese estado de cosas la momia se rebela con la violencia física pero también, como hemos citado anteriormente, resquebrajando las bases de la familia occidental y fundamentalmente anglosajona; la puritana esposa se transforma entre los fuertes brazos de la momia, especialmente en la versión de la Hammer de 1959, quizás la más carnal, valga la expresión, de todas ellas. Porque como también podemos comprobar las momias aparecen de modos muy diversos, no existiendo un modo único a la hora de mostrarlas en las pantallas.

En la versión de 1932, la momia aglutina en su persona los arcanos conocimientos de la civilización egipcia, es ciertamente una amenaza, pero es un peligro oculto cuyo inmenso saber acrecienta la fascinación que le envuelve y transmite. Como ya vimos, en la revisión de la Universal de principios de los cuarenta, aún en los difíciles años de la II Guerra Mundial, el miedo aumenta al no estar la momia en el lejano Egipto, sino que su paso titubeante recorre ya las tierras norteamericanas. La amenaza no solo está entre nosotros, sino que además viene con su propio ejército de sirvientes. Sus modernos seguidores son presentados en estas películas con los mismos rasgos negativos con los que aparecen otros egipcios o por extensión, los personajes orientales de la trama. Nos referimos a directores o responsables de museos, jefes políticos o representantes del orden público de los que subraya el comportamiento corrupto, la ignorancia, la propensión al engaño y la avaricia desmedida.

La saga de películas de momias de la Hammer introdujo una serie de cambios que eran reflejos de los nuevos tiempos; se mostraba en pantalla una violencia mucho más realista así como un modo más permisivo a la hora de mostrar las escenas eróticas. Todo ello ayudado por una impactante fotografía que privilegiaba los colores más agresivos. Y si la momia aparecía como un monstruo de la naturaleza, sus antagonistas occidentales -esencialmente los arqueólogos y hombres de ciencia-, compartían ese mismo carácter monstruoso, especialmente desde un punto de vista moral ${ }^{55}$.

La mezcla de Antigüedad y el género del terror no ha sido una exclusiva, cinematográficamente hablando, de la civilización egipcia. Algo similar, aunque en menor mucho menor medida, ya que el volumen de films realizados es apreciablemente menor, sucede con la civilización etrusca y su reflejo en las pantallas ${ }^{56}$. Una visión que ha subrayado sus aspectos más misteriosos y sanguinarios; creando una -llamémosla así- "atmósfera etrusca" que envuelve la trama. Suele tratarse de crímenes o desapariciones relacionadas con objetos o ambientes funerarios etruscos. Hablamos de películas como L'Etrusco uccide ancora (A. Crispini, Italia / RFA 1972), Assasinio al cimitero etrusco (S. Martino, Italia 1982), o La maschera etrusca (T. Nicolau, Italia 2007).

${ }^{55}$ NAVARRO, A. J. O. c. 49

${ }^{56}$ LAPEÑA, O. "El misterio etrusco resucita en el cine", en Metakinema, no 6, abril 2010. 
En otras oportunidades, como también sucede con la momia egipcia, es el propio etrusco el que retorna desde el pasado para cometer personalmente los crímenes; ese es básicamente el argumento de Curse of faceless man (E. L. Cahn, USA 1958), que se desarrolla en la moderna Pompeya. Similar punto de partida narrativo lo encontramos en Le Notti del Terrore (A. Bianchi, Italia 1981), con la salvedad de que en esta película se mezclan los etruscos que viajan en el tiempo con el subgénero del cine de zombis; la película de Andrea Bianchi se sitúa en un momento -el inicio de los años ochenta del pasado siglo XX-, en donde el cine de terror italiano explotaba por igual el filón del cine de caníbales y el de zombis, y en el que destacan directores con Lucio Fulci -Zombi 2 (1979)-, Ruggero Deodato -Cannibal Holocaust (1981)-, o Umberto Lenzi -Mangiati Vivi! (1980). Los etruscos zombis de Le Notti del Terrore vienen convocados por el descubrimiento de un arqueólogo, y su estética con las desgastadas túnicas tonos ocres recuerda, incluso, a la vestimenta de los templarios sin ojos protagonistas de la obra del director coruñés Amando de Ossorio ${ }^{57}$.

Para ir concluyendo este sucinto repaso a la contaminación de géneros en el cine sobre el Mundo Antiguo queremos hacer unas breves referencias al considerado cine para adultos, tanto en su vertiente erótica como en el llamado cine pornográfico. El elemento erótico -ya sea mediante los personajes o las situaciones de desnudo, bailes, baños o sugerentes escenas de tortura que se planteaban en la pantalla-, ha sido una constante del género, y ya en sus inicios se encuentran abundantes ejemplos; podemos mencionar aquí las diferentes y tempranas adaptaciones de la historia de Salomé -Salome (U. Falena, Italia 1910), Hérode et le roi nouveau-re (Gaumont, Francia 1910), Salome (J. Gordon Edwards, USA 1918), Salome (Ch. Bryant, USA 1923)-, o títulos como, por ejemplo, Le jugement de Phryne (Francia 1899), y La naissance de Venus (Francia 1899) ${ }^{58}$, L Inferno (F. Bertolini \& A. Padován \& G. de Liguoro, Italia 1911), Messalina (E. Guazzoni, Italia 1923) ${ }^{59}$, Dante's Inferno (H. Otto, USA 1924) ${ }^{60}$, Maciste all'inferno (G. Brignone, Italia 1926) ${ }^{61}$, o la cinta atribuida a Gabrielle D'Annunzio Saffo e Priapo (Italia 1921) ${ }^{62}$.

\footnotetext{
${ }^{57}$ Hacemos referencia a la tetralogía compuesta por La noche del terror ciego (1972), El ataque de los muertos sin ojos (1973), El buque maldito (1974), y La noche de las gaviotas (1975).

58 ALOVISIO, S. \& TORRIONE, A. "Filmografia", en BRUSCOLONI, E. \& PRUDENZI, A. \& TOFFETTI, S. La fiamma del peccato. L'eros nel cinema muto, Turín 1997, 143 - 1477, 146.

${ }^{59}$ MARTINELLI, V. Il Cinema Muto Italiano. 1923 - 1931. Roma 1981, 75 ss.

60 ALOVISIO, S. \& TORRIONE, A. O. c. 153. CHITI, R. O. c. 154. BERNARDINI, A. \& MARTINELLI, V. \& TORTORA, M. Enrico Guazzoni, regista pittore. Cosenza 2005, 176 s.

${ }^{61}$ MARTINELLI, V. (1981), O. c. 270 ss. FARASSINO, A. \& SANGUINETI, T. Gli uomini forti, Milán 1983, 145. MARTINELLI, V. "Maciste en el infierno (Maciste all'inferno. Guido Brignone, 1926)", en Nosferatu, IV, 1990, 76 - 77. DALLI' ASTA, M. Un Cinéma Musclé. Le surbomme dans le cinéma muet italien (1913 - 1926). Crisnée, 1992, 252. CHITI, R. O. c. 41.

${ }^{62}$ CHERCHI USAI, P. "Il casi di Saffo e Priapo (1921 - 1922), e le origini del cinema porno", en Bianco e Nero, $\mathrm{n}^{\circ}$ 49, 1, 1988, 109 - 123. ALOVISIO, S. \& TORRIONE, A. O. c. 175.
} 
En el caso específico del péplum el erotismo ha sido uno de sus rasgos definitorios, pues no en vano existen pocos géneros cinematográficos tan abiertamente exhibicionistas como este. Un exhibicionismo que se ocupa por igual de los cuerpos masculinos -focalizados en los músculos hiperbólicos del héroe -, como en el femenino, ya sea el de las malvadas oponentes de los forzudos, el de las esclavas, las bailarinas o las heroínas.

Este aspecto del péplum continuó invariable hasta el abandono del filón a mitad de los años sesenta del siglo XX. Pero a partir de la década siguiente -aunque a fines de los sesenta ya se detectan algunos ejemplos-, se abandona el erotismo naif de las películas de forzudos y las pantallas ofrecen ahora un tratamiento del elemento erótico mucho más explícito y natural.

Quizás el punto de inflexión en el modo de abordar la cuestión habría que ponerlo en Fellini - Satyricon (F. Fellini, Italia 1969), una película extremadamente personal en donde el mundo romano viene tratado como si de una sociedad del futuro se tratara; el director se aproxima a él con la curiosidad y el estupor de un explorador que contacta por vez primera con una civilización desconocida. Aquí, además, son muy evidentes los paralelismos entre los protagonistas principales y el movimiento hippy contemporáneo ${ }^{63}$.

Muy vinculada a la estética visual de la película de Fellini -pues no en vano el responsable de la puesta en escena es el mismo, Danilo Donati ${ }^{64}-$, se encuentra el macro proyecto y debut cinematográfico de la revista Penthouse, nos referimos a la película Caligola del año 1979. El film supone todo un hito dentro del cine sobre el Mundo Antiguo, y no sólo por el circo mediático que se formó a su alrededor o por las demoras judiciales que retrasaron el estreno de la cinta casi más de dos años. Independientemente de los complejos problemas de realización, postproducción y montaje, lo que conocemos hoy como Caligola es un producto serio y adulto que realiza un discurso sobre el poder y sus oscuros mecanismos que supera la visión shakesperiana del mismo tema que poco antes había ofrecido la reconocida serie británica I Claudius (H. Wise, 1976).

El resultado final es una película en donde todavía se percibe el discurso sobre el poder que pretendía Tinto Brass - autor de buena parte del rodaje aunque no así de la fase de montaje y sonorización-, en donde utilizaba el sexo como metáfora del mismo, siguiendo la fórmula que ya le había proporcionado el éxito con Salon Kitty (1976) ${ }^{65}$. Todo

63 ZANELLI, D. "Dal pianeta Roma”, en ZANELLI, D. (Ed), Fellini Satyricon di Federico Fellini, Roma 1969, $13-79,16$ y 22 ss.

${ }^{64}$ BRUNI, A. "Caligola", en en Monamour, il cinema erotico di Tinto Brass, Nocturno Dossier, no 25, agosto 2004, 28 $-29,29$.

65 TENTORI, A. Tinto Brass. Il senso dei sensi, Alessandria 1998, 39. 
ello mezclado con insertos pornográficos filmados por Giacarlo Lui y Bob Guccione, el director de Penthouse que, en definitiva, era la productora y responsable final del proyecto.

El film inauguró el filón de lo que podemos denominar la Caligola explotation, es decir, películas de menores presupuestos y pretensiones que se ocupaban de las costumbres escandalosas de la corte imperial romana, independientemente de quien estuviera al frente de ella. Estas imitaciones oscilaron primero con el terreno de la comedia para derivar finalmente en cintas pornográficas. Los primeros ejemplos vieron la luz antes incluso que el Caligola original; en 1977 se fechan Le calde notti di Caligola (R. B. Montero) ${ }^{66}$, Messalina, Messalina! (B. Corbucci) ${ }^{67}$, que aprovechó directamente algunos decorados, el vestuario e incluso a alguna de las actrices de Caligola, y Per amore di Poppea (M. Laurenti). Pero será ya en los años ochenta del siglo pasado cuando el filón alcance pleno desarrollo con títulos como A Filha de Calígula (O. Fraga, Brasil 1981), Una virgen para Calígula (J. J. Puig, España 1981), Caligola e Messalina (B. Mattei, 1982) ${ }^{68}$, Caligola, la storia mai raccontata (D. Hills, 1982) ${ }^{69}$, Schiave di Caligola (L. Weber, 1984), o Messalina, orgasmo imperiale (O. J. Clarke, $1984)^{70}$; los ejemplos más tardíos, por su parte, serían Caligola, follia del potere (R. De Palma, 1996), Messalina, virgin empress (J. D’Amato, 1996), Caligula's lover boys (V. Iresch, USA 2001), o Caligula sex (Brasil 2003).

Esta corriente o tendencia se va a consolidar en los años siguientes, dando lugar a un volumen de productos que combinan la Antigüedad con el cine para adultos que supera el centenar de títulos ${ }^{71}$. Hay que señalar la dificultad para catalogar debidamente este material, ya que en los años ochenta y noventa muchas de estas películas no se estrenaron en los cines sino que se editaron directamente para el mercado del VHS, primero, y luego del DVD. Con el desarrollo de Internet circulan además muchos títulos difíciles de clasificar correctamente. No hay que olvidar que estas películas pueden volver al mercado al cabo de los años con diferentes títulos y montajes, dependiendo de lo permisiva que resulte la censura de los diferentes países donde se comercializan, sin olvidar que en muchas ocasiones es difícil encontrar un director responsable del resultado final de los productos.

\footnotetext{
${ }^{66}$ BRUSCHINI, A. \& TENTORI, A. Malizie Perverse. Il cinema erotico italiano, Bolonia 1983, 88 s. GIUSTI, M. Dizionario dei film italiani stracult, Milán 2004, 123.

67 "Messalina, Messalina" en Rivista del Cinematografo, no 5, 1978, 220. A. G. "Messaline, impératrice et putain (Messalina Messalina)", en Positif, no 271, 1983, 75. BRUSCHINI, A. \& TENTORI, A. O. c. 89.

${ }^{68}$ GIUSTI, M. O. c. 125.

${ }^{69}$ P. F. "Caligula, la véritable histoire (Caligula, the true story)", en Positif, $\mathrm{n}{ }^{\circ} 271,1983,74$.

70 DELLA CASA, S. "Messalina, orgasmo imperiale”, en Film, n ¹, 1984, 20.

71 Para consultar este material hemos trabajado las bases de datos European Girls Adult Film (www.egafd.co.uk), Adult DVD Empire (www.adultdvdempire.com), y Movie and pornstar databse (www.iafd.com).
} 
Resulta evidente que en estas películas el interés por la adecuada ambientación y el vestuario están reducidos a la mínima expresión; pero este minimalismo formal mantiene algunos de los tópicos sobre el Mundo Antiguo que el cine -heredero de manifestaciones artísticas de los siglos XVIII y XIX-, ha privilegiado y consolidado en el imaginario colectivo. La utilización de determinados colores -blancos, rojos-, y texturas -mármol, terciopelo, pieles de felino-, así como la repetición de unos comportamientos por parte de sus protagonistas ${ }^{72}$, en especial los miembros de la élite gobernante, han seguido transmitiendo una visión muy particular de la Antigüedad. Una crítica hacia las culturas del pasado Mediterráneo, focalizada en los aspectos y comportamientos morales, sexuales y lúdicos, que en el fondo es una justificación del presente, de las estructuras sociales, religiosas, económicas y morales que hacen posible la realización y el consumo de los productos cinematográficos.

La primera conclusión, tras un rápido análisis de este material, es que la figura del forzudo, personaje básico en el género del péplum, apenas tiene interés en su versión en el cine adulto, encontrando apenas algún ejemplo aislado, caso de Le fatiche erotiche di Ercole (J. D’Amato, Italia 1997).

Por el contrario si podemos apreciar tres focos de interés; el primero de ellos sería el mundo egipcio y en especial el filón relativo a las momias, de las que ya comentamos en páginas anteriores la alta carga erótica que han tenido siempre; se incluirían aquí películas como Mummy Dearest (D. Dumont, USA 1990), The Mummy's Dungeon (USA 1993), Apriti...Mumia (M. Dora, Italia 2002), Pharaob (L. Botello, USA 2003), Attack of a virgin mummies (D. Carstensen \& A. Schom, USA 2003), The Mummyx (G. Candiano, España 2005), o The Mummy's kiss: 2nd dinasty (D. F. Glut, USA 2005).

El segundo de ellos se centraría en la Roma antigua, e incluye películas que simplemente se sitúan cronológicamente que en ese periodo, otras que se ocupan de sus personajes más conocidos -el triángulo Julio César/Cleopatra/Antonio, Nerón, Espartaco...-, y finalmente las que explotan el filón de los gladiadores, que curiosamente inspiró tanto a cintas de temática heterosexual -surgidas tras el éxito comercial y mediático de Gladiator R. Scott, USA 2000)-, como de orientación homosexual. Mencionamos como ejemplos, extraídos de una larga lista de títulos, a Flavia (L. Onorati, Italia 1987), Nerone, perversione dell'impero (J. D’Amato, Italia 1996), Antonio e Cleopatra (J. D’Amato, Italia 1997), Gladiator (S. Canterbury, USA 2000), Conquered (C. C. Larue, USA 2001), Gladiator School Orgy

\footnotetext{
72 Infantil, egocéntrico, caprichoso, violento, excesivo...
} 
(USA 2004), Roman Love Temple 69 BC (USA 2005), Spartacus (C. Borbely, USA 2005), Alpha: Centurion Muscle 2 (J. D. Slater, USA 2006), o la trilogía Roma (A. Adamo, Italia 2007 - 2008).

El tercer gran foco de interés sería lo que podemos llamar el mundo bárbaro en el sentido más amplio posible de la expresión, y que incluiría desde los pueblos germanos a las Amazonas pasando por Atila y los galos de Asterix. Y algunos de estos títulos se corresponderían con New Barbarians I (H. Pachard, USA 1990), Amazons from Burbank (C. C. Larue, USA 1990), Amazons, virginal warriors (J. D’Amato, Italia / USA 1996), Hotdorix (A. Payet, Francia 1999), Amazone sex (C. Mourthé, USA 2001), Orgies Barbares (C. Son, Francia 2005), o Land of the Amazons (D. Dakota, USA 2006).

A todos ellos habría que añadirle aquellas otras cintas realizadas aprovechando el éxito puntual de títulos destinados al gran público; serían, por ejemplo, los casos de DunHur (H. Spencer, USA 1994), A Midsummer night's cream (S. Canterbury, USA 2000), Raiders of the lost arse: the mummy's hand (C. Ward \& D. Slater, USA 2002), Alexander the Great Gang Bang (USA 2006), o ya más tangencialmente relacionada con el tema de la Antigüedad, puesto que se ocupa de la figura del arqueólogo, Bikini Jones and the temple of Eros $(\mathrm{N}$. Medina, USA 2010).

En las páginas precedentes hemos tenido ocasión de comprobar cómo el amplio volumen de películas sobre el Mundo Antiguo no se limita, exclusivamente, a aquellas producciones ambientadas dentro de sus límites cronológicos. De hecho, esta capacidad de quebrar las barreras temporales sería uno de sus primeros aspectos positivos. Otra de sus características más significativas, aunque a veces poco resaltada, ha sido la facilidad con la que estas películas se han mezclado, o contaminado, con rasgos y elementos propios de otros géneros cinematográficos.

En un género como el cine sobre la Antigüedad, donde los viajes en el tiempo son tan habituales, ya sean del pasado al presente o desde hoy al pasado, resulta inevitable que las mezclas adquirieran un papel importante. $\mathrm{Y}$ eso sucede desde los inicios del género, donde ya encontramos, claras influencias del melodrama en el Kolossal italiano de comienzos del siglo XX. Desde ese momento en las pantallas hemos podido ver a la Antigüedad mezclada con la comedia, el musical, el western, el terror...

La existencia de la contaminación entre géneros enriquece aún más al cine sobre el Mundo Antiguo como campo de estudios, al hacer posible la realización de análisis de las diferentes obras desde otros puntos de vista novedosos. De este modo se amplían aún más las posibilidades de trabajo con un material fílmico que cada día que pasa va en aumento. 